\title{
Hacia la comprensión de Quem diligit "anima mea" en la teología mística de Guillermo de Saint-Thierry
}

\author{
EVA REYES-GACITÚA \\ Universidad Católica del Norte (Chile) \\ ereyesg@ucn.cl
}

\begin{abstract}
Resumen
A partir de la expresión Amado de mi alma, Guillermo de Saint Thierry subraya uno de los elementos principales de su doctrina espiritual. A partir de la Expositio in Canticum Canticorum, nuestro autor comenta cómo la Esposa elogia al Esposo a través de esta fórmula, confiriéndole en ello, un sentido particular en la relación de los amados; pues este amor tiene un cierto gusto de aquel a quien busca: sensum quemdam. Amor que es comunicado al hombre para que él ame a Dios, como Dios se ama. Por ello, la Esposa dice a los centinelas: “¿Habéis visto al amado de mi alma?”. Estas palabras no solo denotan su afecto, sino permiten considerar que el alma misma experimenta la presencia de Dios. Guillermo de Saint Thierry ofrece una analogía en la que intenta transmitir que en esta comprensión del amor, el amante se transforma en el amado. Palabras clave: Guillermo de Saint-Thierry, Amado, Cantar de los Cantares, Sensum quendam, Espíritu Santo.
\end{abstract}

\section{Toward the comprehension of Quem diligit "anima mea" in the mystical theology of William of Saint-Thierry}

\begin{abstract}
From the expression Beloved of my soul, William of Saint-Thierry highlights one of the main elements of his spiritual doctrine. From Expositio in Canticum Canticorum, the author comments how the Bride praises the Bridegroom through this formula, thus giving it a particular sense in relation to the beloved ones because this love somehow likes the one he looks for: sensum quemdam; love that is communicated to man so that he can love God, as God loves himself. For this, the Bride says to the sentinels: "Have you seen the beloved of my soul"? These words do not only reveal her affection, but also allow considering that the soul itself experiences the presence of God. William of SaintThierry offers and analogy to transmit that, in this comprehension of love, the lover becomes the beloved one.
\end{abstract}

Key words: William of Saint-Thierry, Beloved one, Song of Songs, Sensum quendam Holy Spirit.

Doctora en Teología por la Pontificia Universidad Católica de Chile. Actualmente académica e investigadora en la Universidad Católica del Norte, en su Casa Central de Antofagasta (Chile). Autor de varias publicaciones, entre otras "La voz del Amado": palabras de promesa y realidad del entendimiento en el Comentario al Cantar según Gregorio de Nisa (2011); El mito de la caída: aportes desde la hermeneútica simbólica de Paul Ricoeur y el rabino Nilton Bonder (2012). Miembro de la Asociación Internacional de Estudios Patrísticos AIEP.

Recibido: 27/Noviembre/2016 - Aceptado: 8/Enero/2017 


\section{Preliminares $^{1}$}

Paul Verdeyen afirmaba: "hasta medio siglo atrás se encontraba un Guillermo de Saint Thierry a la sombra de la historia...esta atribución abusiva ha disimulado totalmente la fisonomía particular y la doctrina personal de Guillermo" (Verdeyen, 1990: 3). Con ello, intentaba explicitar por qué nuestro autor, por mucho tiempo, se ubicó detrás de su amigo Bernardo de Claraval; a quien veneraba como un hombre santo y cuya biografía redactó en sus últimos años de vida (Ruh, 1990a: 282). Los dos abades se encontraron en la corte del obispo de Guillermo de Champeaux; allí Guillermo era reconocido por su figura deteriorada y humilde, al lado de su compañero de gran presencia (Ruh, 1990a: 282).

De nuestro autor, sabemos que contó con una formación amplia y erudita, nació en Lieja entre el 1075 y 1080 (Verdeyen, 2003: 331; Piazzoni, 1994: 456; Rydström-Poulsen, 2002: 252; Montanari, 2006: 23), de familia noble y dotado de una gran preparación. Junto a Bernardo vivió un período de mutua influencia, donde ambos comentaron el Cantar de los Cantares de Orígenes. Extrañamente varias de sus obras fueron atribuidas a su amigo (Piazzoni, 1994: 457; Bérubé 1991: 119). Hoy en día, la historia ha intentado recuperar el lugar de Guillermo de Saint Thierry y en esta línea, E. Gilson, reconoce al teólogo y al místico. De este modo nuestro autor comienza a dejar de ser un desconocido (Gilson, 1980: 216). Muere el 8 de septiembre de 1148 (Dechanet, 1967: 1243; Gobry, 1998: 54) o 1049 (Dinzelbacher, 1998: 186), después de una corta enfermedad (Montanari, 1997: 264) en la comunidad cisterciense de Sygny, monasterio fundado en la región de las Ardenas belgas (De La Torre, 1993:11).

El presente trabajo se detendrá en la formulación: Quem diligit "anima mea”, para explorar uno de los elementos principales de la doctrina teológica-espiritual de Guillermo de Saint Thierry. Pues, el amor expresado como sensum quendam confiere un fundamento antropológico Trinitario en la vida del creyente. Sin embargo, ¿es posible identificar el Espíritu Santo con el amor mismo del alma? Para resolver tal pregunta, se abordará el texto Expositio in Cantica canticorum, a partir de una lectura analítica-com-

1 Parte de este trabajo fue presentado en el VI Congreso Internacional de Literatura, Estética y Teología. "El Amado en el Amante, Figuras, textos y estilos del amor hecho historia”. 17, 18 y 19 de mayo de 2016, con la disertación plenaria: El Amado de mi alma. Analogías y conceptos en la teología mística de Guillermo de Saint Thierry. ALALITE, Buenos Aires. Cuya participación fue financiada por el Proyecto VRIDT N ${ }^{\circ} 290201$ 10201311. Fondo concursable asistencia a Congresos Internacionales 2016, por la Universidad Católica del Norte. El texto ha sido revisado y profundizado para su publicación. 
plexiva. A modo específico, tres ejes permitirán comprender esta formulación. El primero de ellos en base a la sexta estrofa del Cantar "He buscado al que ama mi alma"; segundo, se penetrará en la comprensión teológica "Lo que nos ha sido dado, lo hemos recibido"; más el tercero y último eje: Amare, Intelligere y Fruere, que permitirán verificar la concatenación de los argumentos en torno al dinamismo trinitario. Finalmente, la conclusión permitirá confirmar el lugar de la pregunta planteada.

\section{He buscado al que ama mi alma}

En la sexta estrofa del Cantar $^{2}$ 3,1-2, la esposa realiza la búsqueda de Dios: "En mi pequeño lecho, por la noche, he buscado al que ama mi alma"’3. Ella había sido elegida para contemplarle; sin embargo, no puede gozarlo incesantemente. Él se escapa y parece abandonarla. Por esta razón, le busca ansiosamente y escudriña aquella noche que parece no dar frutos. Según Guillermo de Saint Thierry, la noche puede ser comprendida como carencia de luz, es aquel lugar donde los ojos se abren en vano en medio de las tinieblas. No obstante, es allí donde la esposa se esfuerza en contemplar lo que desea con su razón (CCEE: 186). A pesar de ello, nuestro autor, ve en esto algo bueno, porque la noche oscura tiene por una parte el efecto de acrecentar el deseo de la cercanía de Dios y por otra, aumentar el conocimiento de sí mismo (Buchmüller, 1998: 244-245). Para K. Ruh, en este sentido, Guillermo se encuentra proponiendo una teología con mucho compromiso, pues allí encuentra su más grande propósito espiritual: la unión de Dios y el hombre (Ruh, 1990a: 282). En fin, esta es la búsqueda de Dios que realiza la esposa en la noche, donde la oscuridad de esta vida, las densas tinieblas o las noches de las tentaciones no la podrán intimidar.

2 Sancto Theodorico, G. (1997). Opera omnia, pars II. Expositio Super Cantica Canticorum, Corpus Christianorum, Continuatio Mediaevalis. Brepols LXXXVII: Turnholti. La obra en latín será citada en adelante: "ExCC 02, LL 002 \5,21" (que se ha de traducir de la siguiente forma: Expositio Cantica canticorum (Número del Cantar, Línea, Parágrafo, número de página). Saint Thierry, G. (1979) Comentario al Cantar de los Cantares. Traducción del texto latino y de las notas de Roberto Thomas: Hna María Rosa Suárez (Padres Cistercienses, 6): Buenos Aires. La versión en castellano se encuentra citada como CCEE (Cantar de los Cantares Edición Española, seguida del número que corresponde al parágrafo del texto), ejemplo: "CCEE 21". También se encontrará el texto en español citado: ej. "CCEE pág. 65. Citando nota a pie de página 156". (Esto significa: Cantar de los Cantares Edición Española, seguido del número de página. Citando la nota a pie de página número 156), para este caso me ha parecido importante lo que afirma el Padre R. Thomas en las notas a pie de página indicadas en la versión castellana del texto del Cantar.

3 ExCC 40, LL 001 \$182,123. In lectulo meo per noctem quaesivi, quem diligit anima mea.

VERITAS, Nº 36 (Abril 2017) 
De este modo la esposa, “...busca al Esposo y no halla sosiego ni de día ni de noche...” (CCEE:188) ${ }^{4}$. Por esta razón, nuestro abad percibe la importancia de las vigilias; pues aquellos que las practican saben bien las oportunidades que estas proporcionan para la vida espiritual del creyente y qué frutos del espíritu logran los que esperan vigilantes el regreso del Esposo. Entonces, opuesta a la noche, la luz será el elemento esclarecedor de la experiencia mística; donde el alma entiende lo que capta (De La Torre, 1993: 205). Vemos en esta interpretación una cercanía a la comprensión dada por Plotino, quien habló del Bien como "luz que ilumina el intelecto". A su vez, San Agustín en De Civ Dei, VIII, 7 reconoce a los estoicos el mérito de haber visto en Dios a la luz de las mentes (Abbagnano, 1991: 761). W. Buchmüller afirma que Guillermo de Saint Thierry no experimentó la noche como algo destructivo. En su vida testimonia que después de experiencias de gran oscuridad, tras la crisis, él experimentaba consolaciones místicas que lo fortalecían para continuar el camino (Buchmüller 1998: 244-245). En este sentido la noche es comprendida como símbolo dinámico, poseedora de una connotación afectiva y otra cognitiva; la que puede ser maestra en el camino hacia Dios. A este respecto F. Pinilla plantea que la noche aparece como un concepto privativo, pues es privación de luz, el cual aplicado al itinerario del alma será la "privación del gusto en el apetito de las cosas". Esto viene a significar "según el apetito a oscuras y sin nada", privación en orden a la purgación del alma que precede al encuentro con Dios. Ahora bien, por otra parte, adentrarse en la oscuridad de la noche es avanzar hacia la luz del día (Pinilla, 1998: 21).

Según el abad de Saint Thierry la perícopa mencionada destaca el pequeño lecho, este es el lugar del silencio, donde los sentidos reposan y nada turba al alma. Aquí el cuerpo se dispone al descanso y se encuentra entregado al sueño. De esta forma, el lecho es para el hombre que medita en Dios, algo semejante como lo fue para Job. Esto quiere decir que es un dulce consuelo tras los trabajos del día y de las fatigas de la vida. Idea inspirada en Job 7,13: "Si digo: mi cama me consolará, compartirá mi lecho mis lamentos". Para nuestro autor, el lecho no es el sepulcro de un muerto, tampoco la taberna de la embriaguez, sino el taller del arte espiritual. Este es el lugar de las santas visiones, ya que se revela a quien duerme lo que no ha conocido durante la vigilia (CCEE: 188). En este sentido, Platón consideraba la posibilidad que los discursos realizados en el día, se hayan originados en los sueños (Abbagnano, 1991: 1101).

Para la esposa el lecho dice relación a la intimidad. Por ello, afirma:

4 ExCC 40, LL 010 \$183,123. Sponsa sponsum requirens, neque diem, neque noctem potest habere feriatum. 
Lo busqué en la verdad, por si se encontraba allí, a fin de que, al crecer el amor, pudiera sentirme junto a Él en el gozo de la visión y de la suavidad de la fruición, junto a Él, que siempre suele estar próximo de todos los que lo invocan con verdad (CCEE: 190) ${ }^{5}$.

Guillermo se encuentra citando el Salmo 114,18. Entonces, la esposa dice: "Me levantaré y recorreré la ciudad, por calles y plazas, buscaré al amado de mi alma" ¿cuál es esta ciudad, cuáles estas calles y estas plazas, donde parece que hay que buscar al Esposo sin poderlo encontrar?" (CCEE: 191) ${ }^{6}$. Según el abad, existe un sentido más o menos claro de lo que significa esta ciudad. Se trata de aquel lugar citado en el Salmo 54, 10 12 , ciudad de la iniquidad y la discordia, donde ronda el pecado día y noche, lugar de la fatiga y el fraude. Lugar de la traición como es descrito en el Salmo 40,10: "hasta mi amigo íntimo en quien yo confiaba, el que mi pan comía, levanta contra mí su calcañar". Guillermo subraya en alcances dramáticos esta contienda, "donde la carne desea contra el espíritu y el prójimo se levanta contra el prójimo" (CCEE: 192) ". "Por calles y plazas, buscaré al amado de mi alma”. Guillermo pregunta ¿qué significa esto? ¿acaso el Esposo se encuentra en medio de la gente? ¿anda por las calles y plazas? La respuesta parece ser clara: puesto que el amor es impaciente, cree que debe buscar por todas partes al que ama; por tanto, no imagina ningún lugar que no pueda encontrar cuando quisiera (CCEE: 197).

Para nuestro autor, la expresión "amado de mi alma" dice relación al espíritu que da vida. En el Cratylus de Platón el alma ya era considerada causa de la vida (Abbagnano, 1991: 34). En el Antiguo Testamento recordamos a Adán como alma viviente. En este sentido, por alma se comprende la vida misma, cuya función es la de vivificar. De este modo, el alma de la esposa ama y busca al Esposo, porque para ella vivir es Cristo (CCEE: 196). Clara reminiscencia de Filipenses 1, 21: "pues para mí la vida es Cristo, y la muerte, una ganancia". Entonces la esposa ha dicho una vez más "buscaré al amado de mi alma”. Según Guillermo, ella es la doliente, que al ver escapar al que tiene junto a sí, recorre todos los lugares y las ocupaciones de toda clase de hombres, de todo género de vida. Tras la ausencia, ahora todo le provoca náuseas: ha quedado lejos aquello que era agradable

\footnotetext{
5 ExCC 40, LL 066 \ 186,125 Quaesiui utrum ibi esset in ueritate quaerendi, ut, proficiente ordine caritatis, ipsa quoque cum illo adessem in videndi gaudio et fruendi suauitate, qui semper prope esse solet omnibus inuocantibus se in ueritate.

6 ExCC 41, LL 001 \ 187,125 Surgam et circuibo civitatem; per vicos et plateas quaeram quem diligit anima mea.

$7 \quad$ ExCC 41, LL 011 \$187,126. Ubi caro concupiscit aduersus spiritum, siue proximus aduersus proximum.
}

VERITAS, No 36 (Abril 2017) 
a la vista, sabroso al gusto, armonioso para el oído, perfumado al olfato, suave al tacto, todo aquello cuya posesión era deseable, donde el goce se volvía delicioso (CCEE: 197). De este modo, su amor la hace inestable, la intención la lleva de un lugar a otro; donde el afecto inmutable es causa de todas sus fluctuaciones (CCEE: 197). Ella busca por todas partes, esperando encontrar a aquel que, a veces, se suele hallar, aun donde no se espera (CCEE: 197).

Sintetizando, Guillermo se encuentra comentando el Cantar de los Cantares. Allí expone su doctrina teológica espiritual con un marcado acento de la búsqueda del hombre hacia Dios. En este sentido la riqueza de analogías "noche", "lecho", expresan la dificultad del encuentro pleno, sin embargo, permiten entrever la dimensión del misterio ante la cual el hombre se presenta. Ahora bien, la expresión "Amado de mi alma" comporta una singularidad en las relaciones de los que se aman. El alma es lo más personal del hombre y Guillermo quiere proponer una perspectiva teológica diferente a lo pensado en su época.

\section{Lo que nos ha sido dado, lo hemos recibido}

En el Comcant el Esposo se había acercado a la esposa, saltando sobre los montes y pasando de un brinco sobre las colinas. Había mirado por las ventanas y espiado por las celosías y allí había encontrado a la esposa dedicada a la ociosa ocupación -o al ocio ocupado- del tiempo libre, ocupada y preocupada de aquello que le atañe al pequeño lecho. Entonces la había despertado una vez, dos veces, tres veces, invitándola a que se levantara y se apresurara a venir a su encuentro. La había invitado a penetrar en los ocultos misterios de su amor, a contemplar más plenamente su rostro, a esforzarse por conocerlo más claramente, a tender las mejores recompensas en la bienaventuranza eterna. Luego se había ido y, volviendo al secreto de su divinidad, le había escondido su rostro, tan deseado que, no solo los ángeles en el cielo, sino también los hombres; émulos de la perfección angélica, ansían contemplar en la tierra. De este modo, había puesto su escondite en las tinieblas (CCEE: 198). Ahora bien, este movimiento no describe una completa ausencia; sino en el sentido de Dionisio Areopagita (1995: 373), posibilita a la esposa, penetrar en el interior mismo de la tiniebla luminosa en la que acabará toda búsqueda.

Esto quiere indicar que por las constantes visitas del Esposo, la esposa se había vuelto perezosa y remisa para los ejercicios espirituales. Al ser llamada no se levanta, ni se apresura, sino se limita a pedir que Él regrese más a menudo, diciendo: "Vuelve, pues, Amado mío; sé semejante a una 
cabra y a un joven cervatillo" (CCEE: 183) ${ }^{8}$. Entonces, al ver que no regresa ante su ruego, se vuelve de un lado a otro, pidiendo los besos y los abrazos a lo que estaba acostumbrada, pero sin entregarse al trabajo que requiere el ejercicio espiritual (CCEE: 198).

Finalmente, como el Esposo tarda, ella comprende que debe levantarse, que le es más útil salir cuando el Esposo se lo ordena, que permanecer sola en el lecho de su reposo y que, estando ausente el Esposo, no es descanso, sino pereza permanecer en él (CCEE: 198). Por esta razón la esposa deja el lecho y comienza la búsqueda: "Me levantaré...y recorreré la ciudad; por calles y plazas, buscaré al amado de mi alma" (CCEE: 192)․

Guillermo comenta que cuando el Esposo se va, huyen y desaparecen los consuelos que experimenta la esposa. Es el momento cuando el espíritu se torna estéril, pues ya no produce frutos de antaño, entonces su amor no tiene impulso, su pensamiento y su inteligencia se ven privados del fruto de la devoción (CCEE: 199). Este es el momento cuando exclama nuevamente: "me levantaré e iré dondequiera que me impulse el fuego de mi amor o, más bien mi deseo; lo seguiré a dondequiera que me arrastre" (CCEE: 199$)^{10}$. Pareciera que ahora ella es indigna de las visitas del Esposo; de modo que busca entonces a aquellos a quienes el Esposo goza (CCEE: 197).

Seguidamente la esposa exclama: "Me encontraron los centinelas, los que guardan la ciudad" (CCEE: 200) ${ }^{11}$. Nuestro autor dirá que los centinelas son aquellos espíritus servidores, que cuentan con la misión de asistencia para quienes han de heredar la salvación. Idea que remite claramente a Hebreos 1,14. También pueden ser, los santos doctores y predicadores que cuentan con un puesto de guardia, para custodiar a la Iglesia (CCEE: 200). Los centinelas también pueden ser los ángeles, que protegen y ayudan a la esposa, según Guillermo ellos tienen misteriosos medios para sugerir advertencias e inspirar consejos saludables (CCEE: 200). En efecto, "encontraron a la que buscaba, a la que la gracia había transformado en amante" (CCEE 202) ${ }^{12}$. De otro modo, ellos no la habrían podido hallar, si esta misma gracia no se los hubiera anticipado.

$8 \quad$ ExCC 39, LL $031 \$ 177,120$. Reuertere, dilecte mi, similis esto capreae binnuloque ceruorum super montes Bethel.

$9 \quad$ ExCC 40, LL 078 \$186,125. Vnde sponsa quid in sponsi | egerit absentia, subdendo manifestat: Surgam et circuibo civitatem; per vicos et plateas quaeram quem diligit anima mea.

10 ExCC 042, LL 050 \$193,130. Surgam ergo, inquit, ibo quocumque me amoris, uel potius desiderii mei aestus rapuerit, sequar quocumque traxerit.

11 ExCC 042, LL 060 \$194,130. Inuenerunt me vigils, qui custodiunt civitatem.

12 ExCC 042, LL $090 \$ 196,131$. Inuenerunt quaerentem, quam gratia $\ulcorner$ iam 7 fecerat amantem. 
Este es uno de los temas centrales de la antropología y la mística guillermiana, también presente en otros textos ${ }^{13}$. Hace referencia a la experiencia interior de la gracia, otorgada por ella misma. En palabras de nuestro abad: "nadie sube hasta ella, si ella no se digna descender a él; nadie experimenta este bien, sino aquel que ha sido conformado a él; nadie vive esta vida, sino el que es vivificado por ella" (CCEE: 202) ${ }^{14}$. De este modo, el amor ha sido derramado en nuestros corazones por el mismo Espíritu Santo que nos es dado (CCEE: 203). Para Guillermo la presencia de la gracia preveniente es la que puede producir algún fruto; por esto la esposa dice a los Centinelas:

"¿Habéis visto al amado de mi alma?" Tiene un sonido, dice, muy distinto para mí, habla a mi alma de una manera muy distinta la voz interior de su dulzura, que el discurso exterior de vuestra predicación. Mi amor tiene un cierto gusto de aquel a quien busco (CCEE: 203) ${ }^{15}$.

Esta índole de expresión asigna al Espíritu Santo una unión con el creyente; es decir, lo que nos ha sido dado, lo hemos recibido a causa del Espíritu de Dios. De este modo, se constata en la presencia de nuestro espíritu al Espíritu. En términos de M. Davy, Dios habita en aquellos que poseen la caridad; es la existencia en Él y solo por Él (Davy, 1954: 241). Esta idea se recoge en la fórmula del hombre capax Dei, altamente desarrollada por los Padres de la Iglesia y la teología medieval. Guillermo lo ha expresado de la siguiente manera:

Ciertamente, no se puede dudar, que para amarte de ese modo, ella ha tenido que ser iluminada alguna vez por el resplandor de tu rostro; para suspirar así por ti, ha sentido de alguna manera la caricia de tu aliento, para abandonarse tan familiarmente a ti, ha experimentado la dulzura de tus abrazos. Pues el amor con que te ama no puede provenir sino de ti, que eres la dilección misma con la que te ama y te ama en sí, en la medida en que ella misma no se ama en ningún otro, sino en ti (CCEE: 54) ${ }^{16}$.

13 Sancto Theodorico, G. (1997). Opera omnia, pars II. Expositio Super Cantica Canticorum, Corpus Christianorum, Continuatio Mediaevalis. Brepols LXXXVII: Turnholti. También en otras obras del autor: Meditativae orationes PL 180, 205-248; Epístola af Frates de Monte Dei PL 184, 307-364; Speculum fidei PL 180,365-398.

14 ExCC 042, LL $101 \$ 196,131$ y 132. Ad sublime illud nullus ascendit, nisi cui ipsum condescendit; bonum illud nemo sentit, nisi quem ipsum sibi conformat; uita illa nemo uiuit, nisi quem ipsa ninificat.

15 ExCC 042, LL 110 S 197, 132. Num quem dilexit anima mea vidistis? Aliter, inquit, mibi sonat, aliter loquitur interioris sonus dulcedinis animae meae, aliter exterior sermo praedicationis nestrae. Habet eius quem quaero sensum quemdam dilectio mea, quem tametsi uos quoque habetis.

16 ExCC 10, LL 019 S 051,45. Et certe nequaquam dubitandum est ipsam pulchritudinis tuae faciem aliquando ei illuxisse, quae sic diligit te; spiritu oris tui aliquatenus afflatam, quae sic suspirat 
De este modo, el Espíritu Santo es esa misma dilección de la que habla la esposa cuando dice: "Oh, amado de mi alma" (CCEE: 53) ${ }^{17}$. Sin embargo, el Amor ama sirviéndose de nuestro amor y es aquel que "actúa" nuestro amor. Efectivamente, aquí podemos encontrar un punto álgido en la comprensión guillermiana sobre el don y el donante. Al respecto dirá Paul Verdeyen, tanto Bernardo como Guillermo han tomado de la doctrina origeneana lo que concierne a la naturaleza divina del amor. Si bien es cierto, Guillermo es más circunspecto respecto al empleo de la antítesis "sustancia-accidente"; a la cual el Doctor melifluo se adscribe - entendiendo caridad como res Dei et donum Dei-, Guillermo ponderará las relaciones divinas (Verdeyen, 1990: 205-206). Esta comprensión destaca un lineamiento doctrinal en nuestro abad, pues a partir de la relación dondonante intenta rechazar las diferencias, enfatizando la semejanza en la desemejanza.

Esta manera de pensar penetra en el fundamento teológico ya expuesto en el Concilio de Letrán IV (1215): similitudo mayor sit dissimilitudo(Denzinger \& Hünerman, 2000: 806) ${ }^{18}$. Es la comprensión de la in-existencia es decir, el uno no se encuentra sólo frente al otro, sino existe uno en el otro. Para L. Malévez, Guillermo parece hablar de una unión de nuestro espíritu, no con la tercera persona, sino con la misma Trinidad (Malevez, 1932: 201). Estos elementos son decisivos para responder la preguntada planteada en cuánto ¿es posible identificar el Espíritu Santo con el amor mismo del alma? Guillermo en el Comcant amplía el sentido de este núcleo dogmático, con la siguiente formulación

Allí, en efecto, se realiza esa unión admirable, esa mutua fruición de la suavidad, de la alegría incomprensible, inimaginable aun para aquel que la experimenta, entre el hombre y Dios, el espíritu creado y el increado. Se los llama Esposa y Esposo, y la lengua humana busca las palabras para expresar, de alguna manera, la dulzura y la suavidad de esta unión, que no es otra que la unidad del Padre y del Hijo, su beso mutuo, su abrazo, su amor, su bondad

ad te; expertam suauitatem amplexum tuorum, quae tam familiariter resoluitur in te. Diligit enim te nonnisi de te, qui es ipsa dilectio, qua diligit te; et in tantum diligit te in se, ut seipsam in nullo diligat nisi in te.

17 ExCC 10, LL 011 \50, 45. quia Spiritus sanctus ipsa dilectio est, de qua dicit sponsa: $O$ quem diligit anima mea.

18 Cum vero Veritas pro fidelibus suis orat ad Patrem: "Volo", inquiens, "ut ipsi sint unum in nobis, sicut et nos unum sumus" (Io 17,22): hoc nomen "unum" pro fidelibus quidem accipitur, ut intelligatur unio caritatis in gratia, pro personis vero divinis, ut attendatur identitatis uñitas in natura, quemadmodum alibi Veritas ait: "Estote perfecti, sicut et Pater vester caelistis perfectus est" (Mt 5,48), ac si diceret manifestius: "Estote perfecti" perfectione gratiae, "sicut Pater vester caelestis perfectus est" perfectione naturae, utraque videlicet suo modo: quia inter creatorem et creaturam non potest tanta similitudo notari, quin inter eos maior sit dissimilitudo notanda.

VERITAS, No 36 (Abril 2017) 
y todo lo que, en esta unidad infinitamente simple, es común a ambos. Todo esto es el Espíritu Santo, Dios, caridad, donante y don al mismo tiempo (CCEE: 95) ${ }^{19}$.

Paul Verdeyen afirma, que Guillermo ha presentado la perfección de la vida espiritual en términos tradicionales y novedosos. Su originalidad se encuentra en una aproximación más subjetiva, quizás más sicológica de la realidad espiritual, que ha intentado expresar. De hecho, la expresión "unidad de espíritu" remonta a san Pablo 1 Cor 6,17, la que también ha sido expuesta por Orígenes, los padres griegos y latinos (Verdeyen, 1990: 235). Según K. Sander, el abad de Saint-Thierry usa amplexus o Unitas spiritus, para esta indescriptible unión (Pfeifer, 1999: 345). Él está consciente que estos términos tienen un carácter de ayuda para expresar lo que siente y al mismo tiempo otorgan valor a la precisión, tanto en la formulación teológica de los pensamientos como en lo linguístico. Este es el sentido notable cuando el autor comenta la Expositio In Canticum y afirma: et fiat mutua visio, mutuus amplexus, mutuum gaudium, unus spiritus ${ }^{20}$.

Guillermo llama Unitas spiritus a la más alta comunión del hombre con Dios, es un ver cara a cara en el que somos capaces de contemplar a Dios en lo que Él es, pero no quién Él es. En otras palabras, es la inhabitación de Dios en el alma humana. Este conocimiento en el amor, ya sea a través del éxtasis o el transitus, es el amplexus de la novia con el novio en el que se sobrepasa el status del ser humano supra hominem est (Ruh, 1990b: 24).

En síntesis, Guillermo como Bernardo, han encontrado un fundamento sólido en la doctrina de Orígenes que dice res quidem Dei et munus ejus est caritas. Para Guillermo la propia personalidad del Espíritu Santo hace posible la unidad y reciprocidad de Dios Padre e Hijo por una parte y de Dios y el hombre por otra.

\section{Amare, intelligere y fruere}

Guillermo de Saint Thierry destaca un dinamismo trinitario en el hombre. Según Juan María de La Torre, tres verbos aparecen resumiendo la acción del Espíritu Santo en el hombre: amare, intelligere y fruere.

19 ExCC 20, LL 010 S91,70. In hoc siquidem | fit coniunctio illa mirabilis, et mutua fruitio suanitatis, gaudiique incomprehensibilis, incogitabilis illis etiam in quibus fit, hominis ad Deum, creati spiritus ad increatum; qui sponsa dicuntur ac sponsus, dum uerba quaeruntur quibus lingua hominis utcumque exprimi possit dulcedo et suauitas coniunctionis illius, quae non est alia quam unitas Patris et Filii Dei, ipsum eorum osculum, ipse amplexus, ipse amor, ipsa bonitas, et quicquid in unitate illa simplicissima commune est amborum; quod totum est Spiritus sanctus, Deus caritas, idem donans, idem et donum.

20 ExCC 33, LL 039 \$ 152,107. 
Amare dice relación a un primer movimiento dado, es Dios quien nos ha amado primero. En la Expositio super Cantica canticorum, la esposa se encuentra en una actitud de total adhesión hacia su Señor, pues Dios la ha amado primero y ella es amada en la medida en que es capaz de amar (Ruh, 1989-1990: 83). Según nuestro autor, en el Comcant el Espíritu Santo es comprendido como Amor, el cual se apodera del amor del alma como de un instrumento y le hace amar de una manera que le es propia y que le sobrepasa. Es un acto humano y divino a la vez (CCEE: 111). Para Guillermo el amor recibido del Espíritu Santo como don, es el mismo Espíritu Santo. Según K. Ruh esta es una doctrina que Pedro Lombardo más tarde trataría recogiéndola en sus Sentencias, y a través de la cual llegó a ser conocido por todos (Ruh, 1990b: 22). Si el hombre ha sido creado a imagen de Dios, es para que recordándolo, llegue a conocerlo y conociéndolo humildemente, llegue a amarlo y amándolo, pueda gozar de su experiencia. Para Guillermo de Saint Thierry la unión del alma con Dios inserta al hombre en las relaciones trinitarias, y estas relaciones personales de la Trinidad le ayudan a comprender y encontrar su corazón unificado, del que dimanan todas las facultades humanas (De La Torre, 1993: 200).

Intelligere, indica que nunca se puede entender las cosas de Dios al margen del hombre; como no se puede comprender al hombre solo en sí mismo. Esto nos indica que el verdadero conocimiento penetra en el ámbito de la Trinidad (De La Torre, 1993: 237). Guillermo lo expresa de este modo

Bajo la acción del Espíritu Santo, el espíritu del hombre y el sentido iluminado del amor alcanzan a veces de ellos una visión fugaz; entonces el alma amante se llena de dulzura y es arrebatada por lo que más bien es amado que pensado, saboreado que comprendido (CCEE: 99) 21.

En el Cantar, la inteligencia dice relación a la fe iluminada, esto es la luz iluminante: lumen illuminans, en el acceso del hombre hacia Dios, el amor de aquello que ama ipse amor amantis y dado por gracia; en recompensa de la fe que escucha, la fe iluminada pro fide auditus (Davy, 1954: 218). Fe iluminada, amor iluminado, entendimiento y voluntad iluminados, todas son expresiones que se refieren a una misma realidad: el amor es conocimiento (De La Torre, 1993: 191). Según nuestro abad, la fe iluminada, tiene que ver con una cierta penetración de nuestra inteligencia a los misterios divinos. En sentido general, los creyentes poseen una fe común, ex

21 ExCC 20, LL 071 S95,72. Nam per Spiritum sanctum spiritui bominis, et sensui amoris illuminati, passim raptim, aliquando illuc attingenti, dulcescit illud quicquid est, et rapit amantem, amatum potius quam cogitatum, gustatum quam intellectum.

VERITAS, Nº 36 (Abril 2017) 
auditu y la fe iluminada sería privilegio de quienes se perfeccionan en la caridad (Davy, 1954: 219). A través de la obra, Guillermo deja entrever una relación entre la inteligencia que da su asentimiento; su adhesión a la palabra revelada y el acto de la fe iluminada que hace comprender la significación de estas verdades (Davy, 1954: 220).

Esta idea será desarrollada en su teología mística como "los ojos del corazón iluminado", citado de Ef 1,31. Ahora bien la encarnación se concibe como bajada por etapas, en cuanto el Encarnado se ha unido estrechamente a la humanidad por su condescendencia y este descenso de Dios imparte en el hombre una fuerte tendencia a progresar en la esperanza (Meis, 2001: 38 y 39). Para Guillermo es el Esposo quien infunde por el soplo de su amor en la inteligencia de algunos grandes hombres la fe en estos saltos, esta sería la fe iluminada (CCEE: 150).

La venida del Esposo es adveniencia "aproximaos a Él y seréis iluminados" (Sal 33,6). En este sentido, mediante el Espíritu Santo, la esposa participa en alguna medida de la ciencia universal de Dios. Por ello la esposa en cierta medida es esta luz. Reminiscencias del texto de Sal 88,16: "...a la luz de tu rostro caminan, oh Yahveh"; Sal 4,7: "muchos dicen: ¿quién nos hará ver la dicha? ¡alza sobre nosotros la luz de tu rostro!”. Ella hace suyas las palabras del apóstol Pablo en Ef 1,18: "iluminando los ojos de vuestro corazón...”. También un texto de Ef 1,31: "iluminados los ojos del corazón". Estas citas bíblicas fundamentan el deseo de conocer, que anima a la esposa. Esta insistencia en la esposa parece deducir, que no sería evidente para los lectores de Guillermo el hecho de que el amor no rechaza el conocimiento, al contrario, la razón contribuye al crecimiento del amor y el amor aporta un conocimiento nuevo del ser amado: amor ipse intellectus est (Delesalle, 1987: 342). En este sentido para Guillermo la penetración mutua de razón y amor indican la "unidad de espíritu", acto que no depende de nuestra disposición, sino es más bien una obra de la gracia divina (Ruh, 1989:109). Entendido como el amor mismo por el cual Dios ama y se da al mismo tiempo (Davy, 1954: 158). No alcanzable por el propio esfuerzo (Buchmüller, 1998: 233).

Ahora bien, la comprensión de Fruere queda entrelazada a los dos conceptos anteriores, cuando Guillermo afirma "pues lo que se ama, sólo entendiéndolo se ama y tan sólo amándolo se entiende. Únicamente amando y entendiendo se goza de aquello que vale la pena gozar. En esto pues, tener o gozar es entender o amar" (De La Torre, 1993: 158-159). En la fruición la esposa experimenta su semejanza con el Esposo, esta es una mutua fruitio por la cual las gracias de la presencia conforman, vivifican a la esposa para una entera "transfusión" en Dios (Koehler, 1964: 154). Guillermo realiza un contraste entre el amor de deseo y el amor de fruición. 
El primero se comprende como un amor tormentoso, en cuanto es resultante de la ausencia experimentada del Señor, mientras que el segundo se encuentra colmado por la presencia divina. El tormento es provocado por la ausencia defectus y la voluntad ante ello se encuentra frustrada. Con este amor tormentoso se contrasta la suavidad de la alegría de la fruición que es perfecta, en otras palabras, es la gratuita experiencia de su presencia (Koehler, 1964: 142-143). Nuestro autor se refiere a la fruición eterna, distinta de las visitas del Esposo en esta tierra, por ello afirma:

Cuando, con la apariencia de este mundo, haya pasado toda iniquidad, entonces también pasarán todas estas exigencias y la unión del Esposo y la esposa será plena y perpetua en la plenitud de la semejanza, porque no solamente el Esposo será visto tal cual es, sino que toda alma que haya merecido ser esposa será semejante a Él. También el beso será pleno cuando, mirándose mutuamente a los ojos y una en brazos del otro, la fruición se haga plena y perfecta (CCEE: 98) 22 .

Por esta fruición perfecta el alma entrará en el gozo de su Señor según Mt 25,21 . Este no es un gozo que termina, sino un Sabat, un reposo por excelencia, dado al pueblo de Dios a través del trabajo de la tierra. Es una realidad casi divina que impide a la esposa desfallecer (Koehler, 1964: 144).

En el Cantar, Guillermo expresa esta idea a partir de la vocación a contemplarlo y gozarlo: "Señor Dios nuestro, que nos creaste a tu imagen y semejanza, es decir, para contemplarte y gozar de ti; Tú, a quien nadie puede contemplar hasta gozar, sino en la medida en que se hace semejante a tí..." (CCEE: 1$)^{23}$. En otros términos, Dios es el Arquetipo, a partir del cual el hombre ha sido creado, entonces existe una similitud por naturaleza entre aquello que Dios es y lo que nosotros somos (Vuillaume, 1995: 251), por lo tanto, la doctrina de la Imago y similitudo es la condición básica de nuestra unidad mística con Dios (Ruh, 1990b: 22).

En otras palabras, para Guillermo de Saint Thierry, todo el proceso sensitivo y su análogo, el cognoscitivo, se reduce a una capacidad de conocimiento por parte del sentido o del entendimiento, que implica una semejanza ontológica con el objeto cognoscible (De La Torre, 1993: 158). Esta idea es lo que subyace en 1 Cor 13,12; texto fuente de Guillermo:

22 ExCC 20, LL 057 S 94,71. Cum autem cum figura mundi huius pertransierit omnis iniquitas, tunc etiam pertransibit omnis ista necessitas; et tunc coniunctio sponsi ac sponsa plena et perpetua fiet in plenitudine similitudinis, cum non solum videbitur sponsus sicuti est, sed et quaecumque sponsa esse meruerit, erit sicut et ipse est; fietque osculum plenum, cum oculo ad oculum, amplexu ad amplexum plena fiet et perpetua fruitio.

23 ExCC I, LL $3 \int 1,19$. Domine Deus noster, qui ad imaginem et similitudinem tuam creasti nos, scilicet ad te contemplandum teque fruendum, quem nemo usque ad fruendum contemplatur, nisi in quantum similis tibi efficitur.

VERITAS, No 36 (Abril 2017) 
“ahora vemos en un espejo, en enigma. Entonces veremos cara a cara. Ahora conozco de un modo parcial, pero entonces conoceré como soy conocido". Principio ya formulado por Empédocles y asumido por nuestro autor: lo semejante puede conocerse por lo semejante.

Ahora bien, en este dinamismo trinitario en Guillermo, el Espíritu Santo ocupa un rol, que la teología más tarde denominó nexus. Es decir, esta unidad de amor del Espíritu Santo es lo que provoca nuestra unión con Dios, su inhabitación y también, nuestro cielo (Ruh, 1990b: 287). Es el que adviene por la maravillosa unión entre el hombre y Dios, entre el espíritu creado y el increado (CCEE: 95). Ciertamente, esta reflexión nos aporta una importante idea acerca de la unidad operada por el Espíritu Santo, la que es constatada como un eje transversal en la dinámica esponsal desarrollada.

Entonces por el soplo del Espíritu Santo, el Esposo y la esposa comienzan a estar presentes el uno frente al otro, en la visión cara a cara:

En efecto, cuando, por el soplo del Espíritu Santo, aún en esta vida, por un momento, por un tiempo, nuestra noche se ilumina como el día y se van disipando las sombras de las vanidades seculares, dando paso a la luz de la verdad; y, sobre todo, en el ocaso de esta vida, que es noche y no luz, en la aurora de la otra vida o, más bien, en la mañana de la eternidad, en el día de la resurrección universal, el Esposo y la esposa comienzan a no pertenecerse ya por la fe, sino a estar presentes el uno al otro por la visión, cara a cara, entonces, el Esposo ya no apacentará a la esposa en las flores de la esperanza, a semejanza de los lirios estériles, sino en los frutos de la realidad misma (CCEE: 176) 24 .

El final del destino del hombre será el cara a cara en la eternidad con la Trinidad de las divinas Personas, que los elegidos contemplarán en su unidad, ésta será la fruición por excelencia, la fruición estable, sólida de Dios tras el amor en la fe. Es decir, el amor es la semilla suprema, el punto de partida inicial de todo ser, el principio de causalidad de toda cosa (Davy, 1933: 587). El cara a cara es la fabulosa visión escatológica de la esperanza, no es posibilidad real en nuestra presente condición de los sentidos humanos, sino es la perfecta contemplación y plenitud de la visión en la unión con Dios (Mc Ginn, 1994: 263-264).

24 ExCC 37, LL 006 S 172,117. Cum enim per aspirationem sancti Spiritus etiam in hac uita nox nostra sicut dies illuminabitur ad horam, ad tempus; et saecularium umbrae nanitatum inclinabuntur, cedentes lumini ueritatis; seu magis in occasu uitae buius, quae nox est et non lux, et susceptione matutina alterius uitae, seu potissimum in matutino aeternitatis, in die generalis resurrectionis, tunc sponsus et sponsa incipient sibi non esse per fidem, sed adesse per speciem, facie ad faciem; nec pascet sponsus sponsam instar sterilium liliorum in flore spei, sed in fructu rei. 
Para Guillermo la experiencia mística es próxima a la de Bernardo en la metáfora esponsal sin embargo, se ejecuta una noción original en el rol del Espíritu Santo. En cuanto Él, el amor de fruición, se caracteriza finalmente como unión en la Unidad Trinitaria. Pronto los místicos Flamencos harán referencia de la pérdida en Dios (Koehler, 1964: 158). Claramente reminiscencias de Sal 138,12 “...la noche es luminosa como el día...”; 1 Co 13,12 “... ahora vemos en un espejo, en enigma. Entonces veremos cara a cara. Ahora conozco de un modo parcial, pero entonces conoceré como soy conocido". Nuestro abad comprende que este es el momento de la contemplación de la plenitud, de lo que antes se creía bajo el velo. Es el momento de la posesión de aquello que se esperaba con temor y de la eternidad del gozo de aquello que se amaba a la luz de la fe (CCEE: 177).

Finalmente, al nombrarle como Amado de mi alma, la esposa afirma: "esto tiene un sonido... muy distinto para mí, habla a mi alma de una manera muy distinta la voz interior de su dulzura... Mi amor tiene un cierto gusto de aquel a quien busco" (CCEE: 203) ${ }^{25}$. En ello Guillermo interpreta que el Amor ama sirviéndose de nuestro amor como de un instrumento, que sublima al usarlo (CCEE: 67).

En síntesis, se puede decir que los alcances teológicos son variados: significa que nuestro interior ha sido creado para ir al encuentro de Dios Trinidad: Imago Trinitatis. Por ende, Guillermo ha situado la unitas spiritus como el vértice donde el Espíritu Santo une a sí el espíritu del hombre, formando un solo Espíritu con él, introduciendo al creyente en la participación de la misma vida trinitaria en una relación de mutualidad.

De modo notable y casi único, el texto del Cantar personifica al amor y nos permite afirmar que el hombre aun siendo limitado es a la vez capaz de lo infinito. "...el seno del amor, cuando te ama o procura amarte tal como eres, se dilata, extendiéndose para alcanzar tu grandeza, y entonces alcanza al inalcanzable, comprende al incomprensible" (CCEE: 100) ${ }^{26}$. Nuestro autor expresa esta contradicción a partir de la yuxtaposición de nociones Amor incapabilem capit, incomprehensibilem comprehendit. Estas antítesis señalan el dinamismo de la fuerza del amor, que eleva al alma humana sobre sus propias capacidades, sin embargo, no es el hombre el que tiene éxito por sí mismo:

25 ExCC 042, LL 110 \197, 132. Num quem dilexit anima mea vidistis? Aliter, inquit, mihi sonat, aliter loquitur interioris sonus dulcedinis animae meae, aliter exterior sermo praedicationis uestrae. Habet eius quem quaero sensum quemdam dilectio mea, quem tametsi uos quoque habetis.

26 ExCC 020, LL 097 S 96, 73. Sed amoris, dilatatus sinus, secundum magnitudinem tuam se extends, duma mat te, uel amare affectat quantus es, incapabilem capit, incomprehensibilem comprebendit.

VERITAS, No 36 (Abril 2017) 
Cuando el espíritu del hombre merece estar estrechamente unido a Él, el espíritu al Espíritu, el amor al Amor, el amor humano se vuelve en cierta manera divino; y, en adelante, cuando ama a Dios, el hombre ciertamente es el operario, pero Dios es el que obra (CCEE: 100) ${ }^{27}$.

Guillermo ha precisado la pregunta que motiva nuestro análisis; indicando que esta unidad espiritual da al alma mística una nueva sensibilidad, en una palabra, la inteligencia consciente de la realidad divina en ella (Verdeyen, 1990: 235). Entonces, Dios deviene comprehensible para el ser humano; operando en el hombre una renovación profunda que lo restablece en términos de semejanza divina: ressemblance et Unitas Spiritus. Aquí, nuestro autor es continuador de la doctrina de Agustín y es el primero, en la Edad Media, en comprender al Espíritu como amor y don del Padre y del Hijo. Finalmente, ¿qué hay detrás de este concepto?, pareciera no solo un lenguaje que intenta describir una relación; sino una teo-antropología en la cual se define y se comprende la ruta de nuestra propia humanidad.

\section{A modo de conclusión}

El punto de partida de este artículo ha sido explorar la afirmación de la esposa Quem diligit "anima mea". A partir del Cantar, Guillermo de Saint Thierry elabora una antropología sobre la vida espiritual del creyente, donde el espíritu es lo más personal. Este espíritu es el nexo con el Espíritu y dada esta imbricación el hombre es comprendido como imagen de Dios.

Por ello, la expresión: Quem diligit "anima mea", propone uno de los elementos principales de su doctrina teológica. De este modo, nuestro autor desarrolla una línea de importancia sobre la interioridad, como camino de conocimiento y de apertura. Esto será indicativo de un valor de percepción que remonta al hombre mismo, precedido por el amor de Aquel que le ha creado.

Son claras las reminiscencias de sabor agustiniano, a saber, la comprensión de Dios amor, donde al amor corresponde un amante y un amado y, finalmente se comprende como el amor mismo. Sin embargo, el amor ha sido expresado como sensum quendam confiriendo entonces un fundamento antropológico-Trinitario en la vida del creyente. Esta comprensión expresa que el ser humano se sabe entonces sostenido por Dios. Guillermo ha afirmado que por la gracia y el espíritu de filiación se puede tener la confianza que todo lo que pertenece al Padre, pertenece también

27 ExCC 020, LL 102 \96, 73. Cui cum meretur affici spiritus hominis, spiritus Spiritui, amor amori, amor humanus diuinus quodammodo efficitur; et iam in amando Deum homo quidem est in opera, sed Deus est qui operator. 
al hombre. De este movimiento se desprende una actitud de confianza, que solo la tiene quien se sabe hijo de Dios y, con ello, se le ha ubicado al lado del Hijo. Esta modalidad nos introyecta en el misterio central de la encarnación que realiza nuestra salvación. En esta ocasión a partir de la metáfora del matrimonio espiritual, Guillermo nos ha hablado de la proximidad de Dios al hombre, destacando el sentido de reciprocidad.

Guillermo ha redescubierto la significación espiritual del dogma trinitario, que, como don del Espíritu Santo, otorga al alma el conocimiento inter-personal y fundamento de la vida espiritual del hombre. Esta es la relación de subsistencia que lleva a hablar del Espíritu como Amor y Don del Padre y del Hijo. En este sentido, el Espíritu se prolonga a las creaturas y es llamado Don de Dios. Es decir, el amor penetra todos los ámbitos de la vida del creyente y este comienza a querer aquello que Dios quiere y "En Dios el ser humano llega a ser por gracia lo que Dios es por naturaleza".

\section{REFERENCIAS.}

-Abbagnano, N. (1991). Diccionario de filosofía. México: Fondo de Cultura Económica.

-Bérubé, C. (1991). Guillaume de Saint-Thierry source de la pensée franciscaine. Collectanea Franciscana, 61(1-2), 117-148.

-Buchmüller, W. (1998). Die geistliche Lehre des seligen Wilhelm von SaintThierry. Cistercienser Chronik, 105(1), 233-253.

-Davy, M. (1954). Théologie et Mystique de Guillaume de Saint-Thierry. Paris: Librairie Philosophique J. Vrin.

-Davy, M. (1933). Les trois Étapes de la vie spirituelle. D’ après Guillaume de Saint-Thierry. Recherches de Science Religieuse, 23 (5), 569-588.

-De La Torre, J.M. (1993). Guillermo de Saint Thierry: Un formador de creyentes. Madrid: Publicaciones Claretianas.

-Delesalle, J. (1987). Amour et Connaissance. "Super Cantica Canticorum" de Guillaume de Saint Thierry. Collectanea Cisterciensia, 49(4), 339-346.

-Dechanet, J. (1967). Guillaume de Saint-Thierry. D Sp. VI. Paris: Beauchesne.

-Dinzelbacher, P. (1998). Wilhelm v. Saint-Thierry. Paris: Lexikon des Mittelalters IX.

-Dionisio Areopagita (1995). Obras Completas del Pseudo Dionisio Areopagita, Teología Mistica. Madrid: Biblioteca de Autores Cristianos.

-Denzinger, P. \& Hünermann, P. (2000). El Magisterio de la Iglesia. Enchiridion Symbolorum Definitionum et Declarationum De Rebus Fidei Et Morum. España: Herder.

-Gilson, E. (1980). La théologie mystique de S. Bernard. Paris: Jaca Book.

-Gobry, I. (1998). Guillaume de Saint-Thierry. Maître en l'art d'aimer. Paris: Editions Francois-Xavier de Guibert.

-Koehler, T. (1964). Thème et vocabulaire de la "Fruition divine" chez Guillaume de Saint-Thierry. Revue d' Ascetique et de Mystique, 40(4), 139-160. 
-Malevez, L. (1932). La doctrine de l'image et de la connaissance mystique chez Guillaume de Saint Thierry. Recherche de Science Religieuse, 22(2-3), 178-205; 257-279.

-Meis, A. (2001). El "Rostro de su Gracia". Acercamiento al nexo entre el amor y el Espíritu Santo en la obra de Guillermo de Saint-Thierry. Veritas 9(9), 2950 .

-McGinn, B. (1994). The Growth of Mysticism. Vol II. The Presence of God: A History of Western Christian Mysticism. New York: Crossroad.

-Montanari, A. (2006). "Per figuras amatorias" L'Expositio Super Cantica Canticorum di Guglielmo di Saint-Thierry: Esegesi e teologia. Roma: Analecta Gregoriana

-Montanari, A. (1997). L'amicizia nei monasteri cistercensi del XII Secolo. Rivista Cistercense, 14(3), 255-290.

-Piazzoni, A. (1994). El primer biógrafo de San Bernardo: Guillermo de Saint Thierry. La primera parte de la Vita Prima como obra teológica y espiritual. Cistercium, 46(198), 453-470.

-Pinilla, F. (1998). Los sentidos espirituales en particular: el "toque de Dios" en San Juan de la Cruz, OCD, Doctor de la Iglesia. Anales de la Facultad de Teología, 49(2) 1-196.

-Pfeifer, M. (1999). Amplexus oder Unitas spiritus? Kai G. Sander neue Studie zur Geist-Mystik Wilhelms von Saint-Thierry. Cistercienser Chronick, 106(4), 341-350.

-Ruh, K., (1989). Die Augen der Liebe bei Wilhelm von St. Thierry. Theologische Zeitschrift, 45(2-3), 103-114.

-Ruh, K. (1989-1990). Amor deficiens und Amor desiderrii in der Hoheliedauslegung Wilhelms von St. Thierry. Ons Geestelijk, 63/64(2-4; 1-3), 7088.

-Ruh, K. (1990a). Geschichte der abendländischen Mystik. Erster Band. Die Grundlegung durch die Kirchenväter und die Mönchstheologie des 12. Jahrhunderts, München: Verlag C.H. Beck.

-Ruh, K. (1990b). Die Hoheliederklärungen Bernhards von Clairvaux und Wilhelms von St. Thierry, Studien zur frühen abendländischen Mystiktradition, Stuttgart-Bad Cannstadt. En D. Schmidtke (Ed.), Minnichlichiu gotes erkennusse (pp. 16-27). Heidelberger Mystiksymposiom.

-Rydström-Poulsen, A. (2002). The Gracious God: "Gratia" in Augustine and the Twelfth Century. Copenhagen: Akademisk Fortag.

-Saint-Thierry, G. (1979). Comentario al Cantar de los Cantares. (R. Thomas \& M.R. Suárez, Trad.) Buenos Aires: Padres Cistercienses.

-Sancto Theodorico, G. (1997). Opera Omnia, Pars Ii. Expositio Super Cantica Canticorum, Corpus Christianorum, Continuatio Mediaevalis. Brepols: LXXXVII, Turnholti.

-Verdeyen, P. (2003). L'itinéraire spirituel Selon Guillaume de Saint-Thierry. Christus, 50(263), 331-342.

-Verdeyen P. (1990). La Théologie Mystique de Guillaume de Saint-Thierry. Paris: FAC Ed. Spirituels. 
-Vuillaume, C. (1995). La connaissance de Dieu d'après Guillaume de SaintThierry. Collectanea Cisterciensia, 57(3), 249-270.

Sumario: Preliminares; 1 . He buscado al que ama mi alma; 2. Lo que nos ha sido dado lo hemos recibido; 3. Amare, intelligere y fruere; A modo de conclusión Referencias. 